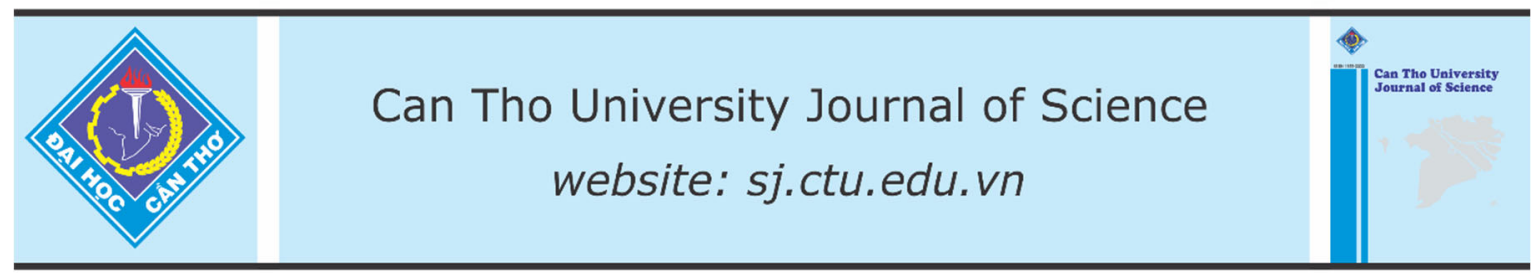

DOI: $10.22144 / c t u . j e n .2019 .016$

\title{
Barriers to women's participation in the Sustainable Rice Platform training course in Ke Sach district, Soc Trang province
}

\author{
Nguyen Huu Loi ${ }^{*}$, Nguyen Hoang Khai and Huynh Quang Tin \\ Mekong Delta Development Research Institute, Can Tho University, Vietnam \\ *Correspondence: Nguyen Huu Loi (email: nhloimdi@gmail.com)
}

\section{Article info.}

Received 24 Jun 2018

Revised 08 Nov 2018

Accepted 29 Mar 2019

\section{Keywords}

Barriers, decision, participating, sustainable rice platform

\begin{abstract}
The study is aimed to investigate the barriers which limit the active participation of women in the agricultural training program in Ke Sach district, Soc Trang province. Household interviews were conducted with the male head as well as spouses of each selected farm families that take part in Sustainable Rice Platform (SRP) training course. The total sample size of the study was 150 respondents (including 75 male and 75 female respondents). A designed structured questionnaire was prepared for the data collection as the research instrument with the three-point and fivepoint Likert scale. The data thus collected were coded on SPSS for analysis and interpretation. Results of the study showed that there was a significant difference in age and educational status of male heads and their spouses. The farming sources are the primary income sources in all households. The intensity of participation of male respondents in different crops, and livestock activities was comparatively high as compared to their female counterparts. Their participation in crops and livestock activities showed that male-headed households had access to agricultural extension services and SRP training course as the same as women' participation. Especially, there are four common factors affecting women's participating decision in SRP training course including: spending too much time on house matters, spending less time on participating social activities, lacking experience regarding production, and depending too much on the decision made by their husbands.
\end{abstract}

Cited as: Loi, N.H., Khai, N.H. and Tin, H.Q., 2019. Barriers to women' s participation in the Sustainable Rice Platform training course in Ke Sach district, Soc Trang province. Can Tho University Journal of Science. 11(1): 112-116.

\section{INTRODUCTION}

Agriculture, one of the oldest economic practices of human civilization, is indeed undergoing a makeover. A large proportion of rural people used to do farming and their livelihoods largely depend upon this profession through direct or indirect means (Dev, 2011). Moreover, in developing countries, agriculture plays an important role in rural livelihoods and poverty reduction (UNDP,
2010). Due to its significance in rural livelihoods in general and in the overall development process, both the genders are involved in activities related to agriculture (Dev, 2011). In some cases, the contribution of women is more than men, and the role of both men and women in farming activities is well established. Gender differentiation in performing different agricultural operations varies from region to region and country to country due to the difference in basic socio-economic structure 
(Wedgwood, 2009). But in major parts of the developing world compared to men, women are facing more constraints in performing agricultural activities thereby reducing their productivity (UNDP, 2010).

Like other developing countries, Vietnam's economy is based on the livelihoods of rural people are mainly associated with this activity. Compared with men, women are also considered as the backbone of the rural national economy due to their significant role in agriculture-based activities. In rural areas women not only perform many agricultural activities, but they are also engaged in other household activities. In spite of the extensive contribution of women in rural economic development, they have the least access to resources as well as other rural development services (Duong, 2001). These constraints not only limit their contribution to agriculture but also create hindrances in the socio-economic empowerment of rural women. This has been observed that most of the agricultural training programs are only addressing both male and female genders and not in the used to their targeted audience (Luqman et al., 2018). As in major parts of the world in general and specifically in developing countries, the head of a household is male, with this factor almost all the agricultural extension and rural development services are being targeted men only (Duong, 2001). Moreover, according to Ortner (1972), her article clearly throws up a great number of issues and in examining her argument we come face to face with some of our most deeply held assumptions about ourselves and the world in which we live. It is true that in most societies women are viewed as having lesser value than men, but this cannot be explained using a culturally specific Western notion of the relationship between culture and nature. Not only are these concepts variable but the very notion of gender can be found to diverge between different societies, and the relationships between gender and power and sex and gender are far from clear-cut. In order to elucidate the position of women in a particular society, the research must examine the complexities and nuances of its social relations and culture rather than imprudently applying our own categories.

In addition, the Sustainable Rice Platform (SRP) is a course for sustainable rice cultivation contains 46 requirements, based on priorities defined in the Performance Indicators, complemented with some priority topics that are essential for the potential destination markets. The requirements are structured under eight themes including (1) productivity, (2) food safety, (3) water, nutrients, pesticides, (4) biodiversity, (5) community, (6) Greenhouse gas (GHG), (7) health and safety, labor rights, child labor, and (8) no applicable (UNEP and IRRI, 2015).

With this background, the objectives of research are to find out barriers affect to decision participating in Agricultural Training Program which is provided evidence from SRP training course in Ke Sach district, Soc Trang province.

\section{METHODOLOGY}

The research is based on the theory "Is Female to Male as Nature Is to Culture" (Ortner, 1972). To the author, nature is referred to as meaning that family with children is a housewife, caring for family members. The culture is referred to as social activities, exchanges with friends, generation income for the family. The survey which is designed a cross-sectional analytical study. The data are gathered through structured questionnaires. The interviews were conducted with 150 respondents in Thoi An Hoi commune, Ke Sach district, Soc Trang province. Respondents answered questionnaires by both three-point Likert scale (high, medium, and low) and five-point Likert scale (strongly disagree, disagree, not sure, agree, and strongly agree).

The information and data obtained from questionnaires were coded and analyzed by SPSS (Statistical Package for the Social Sciences) version 21. In order to investigate the difference in opinion of male and female respondents regarding barriers to existing gender disparity in the research area, a ttest was applied.

\section{RESULTS AND DISCUSSION}

\subsection{Demographic profile}

In view of the significance of demographic characteristics of respondents, for the present study, data were collected regarding some selected demographic characteristics of respondents and tabulated as follows.

\subsubsection{Age}

Table 1 shows that there exists a difference in age of both the categories (male as husband and female as wife) of respondents. The male respondents were older than their partners. Among them, 64\% were older than 46 years old, whereas the percentage was $55 \%$ counted for female group. However, there was $6.7 \%$ women aged 31 or less. This showed that in the majority of the cases, the age of male is higher than female. 
Table 1: Distribution of respondents age $(n=150)$

\begin{tabular}{lcccr}
\hline \multirow{2}{*}{ Age (In Years) } & Male & \multicolumn{3}{c}{ Female } \\
\cline { 2 - 5 } & $\mathbf{n}$ & $\mathbf{\%}$ & $\mathbf{n}$ & $\mathbf{\%}$ \\
\hline Up to 31 years & 0 & 0.0 & 5 & 6.7 \\
32 to 45 years & 27 & 36.0 & 29 & 38.7 \\
46 years and above & 48 & 64.0 & 41 & 54.7 \\
\hline Total & 75 & 100 & 75 & 100 \\
\hline
\end{tabular}

Survey data, 2018

\subsubsection{Education}

Education is very important in the social development. The data regarding the school year was collected and presented in Table 2 .

Table 2 presents the difference in the educational level of male and female respondents. This indicates that the educational status of female is mostly less than their male counterparts (husbands). There were $2.7 \%$ of illiterate females compared to $0.0 \%$ for males. The results also indicate that the majority of rural women completed primary and secondary school (45.3\% and $37.3 \%$, respectively).

Table 2: Distribution of respondents according to their education

\begin{tabular}{lrrrr}
\hline \multirow{2}{*}{ Education/ Years of schooling } & \multicolumn{2}{c}{ Male } & \multicolumn{2}{c}{ Female } \\
\cline { 2 - 5 } & $\mathbf{n}$ & $\mathbf{\%}$ & $\mathbf{n}$ & $\mathbf{\%}$ \\
\hline Illiterate & 0 & 0 & 2 & 2.7 \\
Primary (1-5 years) & 26 & 34.7 & 34 & 45.3 \\
Secondary (6-9 years) & 30 & 40.0 & 28 & 37.3 \\
High school (10-12 years) & 13 & 17.3 & 11 & 14.7 \\
University and above (13 years and above) & 6 & 8.0 & 0 & 0.0 \\
\hline Total & 75 & 100 & 75 & 100 \\
\hline
\end{tabular}

Survey data, 2018

\subsubsection{Participation level of male and female in agricultural activities}

Table 3 indicates that the average daily time spent by a family to crop production and its management related activities was 4 hours and to livestockrelated activities was 4.5 hours. The respondents were further asked to specify the average daily percentage share of female in crops and livestock production related activities. The level of

Table 3: Percentage of workload distribution between men and women in crop and livestock production

(Unit: number of respondents and \% in the bracket)

\begin{tabular}{lrrrr}
\hline \multirow{2}{*}{ Participation level } & \multicolumn{2}{c}{ Crops Production } & \multicolumn{2}{c}{ Livestock Production } \\
\cline { 2 - 5 } & Male & Female & Male & Female \\
\hline None & $0(0.0)$ & $0(0.0)$ & $55(73.3)$ & $55(73.3)$ \\
Low & $4(5.3)$ & $34(15.3)$ & $7(9.3)$ & $0(0.0)$ \\
Medium & $27(36.0)$ & $28(43.3)$ & $10(13.3)$ & $3(4.0)$ \\
High & $44(58.7)$ & $13(41.3)$ & $3(4.0)$ & $17(22.7)$ \\
\hline
\end{tabular}

Survey data, 2018 participation of men and women was assessed on the three-point Likert scale ( $1=$ Low, $2=$ Medium and 3= High) and the data presented in Table 3 . It clearly indicated that the men's crop production activities are higher than the women once, whereas, the level of participation of women was found to be higher than men especially in case of livestock production practices. 


\subsubsection{Level participating in agricultural training course}

It was clear from Table 4 that women along with men were widely engaged in crops and livestock production practices. The major aim of SRP training course in Ke Sach district, Soc Trang Province is to provide sustainable agricultural knowledge to all the community members without discrimination based on social class, income, gender, etc. at their doorsteps. With this notion, participants (both male and female) were determined (Table 4).

Table 4: Participation level in an SRP training course of male and female

(Unit: number of respondents and \% in the bracket)

\begin{tabular}{lrr}
\hline $\begin{array}{l}\text { Level participating in } \\
\text { an SRP training course }\end{array}$ & $\begin{array}{r}\text { Male (Hus- } \\
\text { band) }\end{array}$ & $\begin{array}{r}\text { Female } \\
\text { (Wife) }\end{array}$ \\
\hline No participate & $0(0.0)$ & $39(52.0)$ \\
Low & $30(40.0)$ & $14(18.7)$ \\
Medium & $36(48.0)$ & $10(13.3)$ \\
High & $56(37.3)$ & $12(16.0)$ \\
\hline
\end{tabular}

The data presents that men participated in the majority of the SRP training class session. In spite of the higher participation of females in some cases, they have rarely participated in this course.

\subsection{The factors affect gender participation in training course}

The major objective of this paper was to identify factors affecting women's participation in an agricultural training course in Ke Sach district, Soc Trang Province. Table 5 shows that there were four factors which affectect to women' s participation in the SRP training course - namely spending too much time on home-making, spending less time on exposing to society, lacking production experience, and depending too much on their husbands' decisions. These four factors may be classified into two groups, namely "nature" (including spending too much time on home-making and spending less time on exposing to society) and "culture" (including lacking experience regarding production and depending too much on the decision made by their husband).

Survey data, 2018

Table 5: Ranking of factors affecting participating decision

\begin{tabular}{lrrrrrrr}
\hline \multirow{2}{*}{ Factors affecting } & \multicolumn{2}{c}{ Male } & \multicolumn{2}{c}{ Female } & \multicolumn{2}{c}{ Combined } & \multirow{2}{*}{ P-value } \\
\cline { 2 - 6 } & Mean & SD & Mean & SD & Mean & SD & \\
\hline $\begin{array}{l}\text { Age } \\
\begin{array}{l}\text { Depending too much on the deci- } \\
\text { sion made by their husband }\end{array}\end{array}$ & 2.52 & 1.234 & 2.80 & 1.197 & 2.66 & 1.216 & 0.161 \\
\hline $\begin{array}{l}\text { Lack of information on training } \\
\text { activities }\end{array}$ & 2.64 & 1.051 & 3.35 & 1.180 & 3.30 & 1.116 & 0.560 \\
\hline $\begin{array}{l}\text { Lack of the ability to apply } \\
\text { knowledge gained into practice }\end{array}$ & 3.04 & 1.084 & 2.89 & 1.146 & 2.77 & 1.116 & 0.167 \\
\hline $\begin{array}{l}\text { Lacking experience regarding pro- } \\
\text { duction }\end{array}$ & 3.33 & 1.070 & 3.28 & 1.047 & 3.31 & 1.059 & 0.758 \\
\hline $\begin{array}{l}\text { Not participating in Social Union } \\
\text { (Women's Union, Famer's Union) }\end{array}$ & 3.04 & 0.951 & 3.05 & 0.928 & 3.05 & 0.940 & 0.931 \\
\hline $\begin{array}{l}\text { Spending less time on exposing to } \\
\text { society }\end{array}$ & 3.41 & 1.054 & 3.25 & 0.974 & 3.33 & 1.014 & 0.336 \\
\hline $\begin{array}{l}\text { spending too much time on home- } \\
\text { making }\end{array}$ & 4.29 & 1.075 & 4.45 & 1.056 & 4.37 & 1.066 & 0.359 \\
\hline $\begin{array}{l}\text { The influence of the number of } \\
\text { children in families }\end{array}$ & 3.20 & 1.115 & 2.83 & 1.178 & 2.36 & 1.147 & 0.048 \\
\hline The limit of education level & 3.04 & 1.213 & 3.13 & 1.319 & 3.09 & 1.266 & 0.653 \\
\hline $\begin{array}{l}\text { The limitation on the number of } \\
\text { female agricultural extension of- } \\
\text { ficers }\end{array}$ & 2.16 & 0.698 & 2.55 & 0.890 & 2.36 & 0.794 & 0.040 \\
\hline $\begin{array}{l}\text { The limitations when exposed to } \\
\text { agricultural extension officers }\end{array}$ & 2.11 & 0.981 & 2.15 & 1.238 & 2.13 & 1.110 & 0.827 \\
\hline
\end{tabular}

Survey data, 2018

Scale: 1. Strongly disagree; 2. Disagree; 3. Not sure; 4. Agree; 5. Strongly agree, P>0.05. 
To clarify why ladies are linked with nature, Ortner (1972) asserts that women are the ones who give birth and create novel life. Females are supposed to contribute a large part of own time and body than men, because they have more body organs and functions, for instance, menstruation and breasts, which exist only for the single aim of having children. Mothers at all times have been more connected to youngsters. Certainly, people usually confine ladies to the domestic role, freeing up men to pursue more "cultural" activities, for instance, religion or art (Ortner, 1972). As for kids, they are considered to be the primitive human beings, not yet civilized by the impacts of the culture. As ladies are the ones who raise youngsters, making them sophisticated adults, the author contends women are, therefore, treated as merely the intermediary between culture and nature. Additionally, the author pays attention to the fact that from the psychological point of view, females are more sentimental and emotional than males. Thus, men are more inclined to abstract, "cultures" thoughts, whilst the female's thoughts are more connected to other individuals. Results regarding t-test statistics showed that it is a significant $(\mathrm{P}>0.05)$ difference in opinion of male and female respondents about factors affecting training course participating decision such as lack of the ability to apply knowledge gained into practice, the influence of the number of children in families, and the limitation on the number of female agricultural extension officers.

\section{CONCLUSIONS}

Women play an indispensable role in farming and in improving the quality of life in rural areas. However, their contributions often remain concealed due to some social barriers and gender bias. Social constraints place barriers around their access to scientific and technological information. Furthermore, results show that the barriers include top fourfactors, namely spending too much time on homemaking, spending less time on exposing to society, lacking experience regarding production, and depending too much on the decision made by their husband.

\section{REFERENCES}

Dev, S.M., 2011. Climate change, rural livelihoods and agriculture (Focus on Food Security) in Asia-Pacific Region. Report No. WP-2011-014. Indira Gandhi Institute of Development Research (IGIDR), Mumbai, India.

Duong, W.N., 2001. Gender equality and women's issues in Vietnam: The Vietnamese woman-warrior and poet. Pacific Rim Law \& Policy Journal, 10(2): 191-326.

Luqman, M., Saqib, R., Shiwei, X. and Wen, Y., 2018. Barriers to gender equality in agricultural extension in Pakistan: Evidence from District Sargodha. Sarhad Journal of Agriculture, 34(1): 136-143.

Ortner, S.B., 1972. Is female to male as nature is to culture?. Feminist Studies,1(2): 5-31.

UNDP, United Nations Development Programme, 2001 Learning and Information Pack. Resource 7a Summary of Women's Equality and Empowerment (Longwe) Framework., 49-50.

Wedgwood, N., 2009. Connell's theory of masculinities its origins and influences on the study of gender. Journal of Gender Studies 18 (4):329-39.

UNEP, United Nations Environment Programme and IRRI, International Rice Research Institute, 2015. Standard on Sustainable Rice Cultivation - version 1.0. Program document, accessed on 19 April 2018. Available from http://www.sustainablerice.org/assets/docs/SRP\%20Standard $\% 20$ for $\% 20$ Sustainable $\% 20$ Rice $\% 20$ Cultivation $\% 20 v \% 201.0$.pdf. 